\title{
A GEOGRAFIA DA GRANDE TIJUCA NA ORALIDADE, NO RITMO DAS CANÇÕES E NOS LUGARES CENTRAIS
}

\author{
JOÃO BAPTISTA FERREIRA DE MELLO \\ Universidade do Estado do Rio de Janeiro
}

\section{Considerações iniciais}

A geografia da Grande Tijuca, configurada na oralidade, bem como nos tons e versos registrados pela indústria fonográfica, juntamente com o registro de algumas de suas diversas centralidades, constituem os elementos deste texto. Trata-se de uma tentativa de se estabelecer uma ponte entre abordagens comumente exploradas pelo saber geográfico, como o estudo dos lugares centrais, e instrumentos de análise pouco explorados como a oralidade ou aqueles mais recentemente focalizados pela geografia, como a música popular.

O artigo contempla inicialmente algumas palavras e expressões geográficas consagradas na "boca do povo". Em seguida, a geografia da Grande Tijuca viceja exuberante na cadência dos ritmos e na caligrafia dos compositores da música popular brasileira e, por fim, na emergência e consolidação das centralidades de diversos portes e grandezas. Por Grande Tijuca considera-se um conjunto de bairros da cidade do Rio de Janeiro como Tijuca, Vila Isabel, Andaraí, Praça da Bandeira e Rio Comprido.

\section{A geografia da Grande Tijuca expressa na oralidade}

As pessoas distinguem o(s) seu(s) mundo(s) vivido(s) com apelidos e nomes informais. Tais envolvimentos que brotam com a experiência, a confiança e a afeição revelam intimidade, que na acepção da palavra é a qualidade do "que está muito dentro" ou o "que atua no interior", como apontam os dicionários. Por isso mesmo, os lugares são entes queridos merecedores de considerações especiais. O homem, também, experiencia locais nomeados por outros e a ele passados, notadamente pela educação informal. Designar com nomes, na tradição judaica, significa ter domínio. Os seres humanos dotam com qualificativos as montanhas, os rios, as províncias e os continentes. Essa relação de domínio e intimidade é preciosa, pois contribui para os estágios de pertencimento e interiorização, relevantes no processo de amor ao lugar vivido, ou seja, à sua própria geografia (Tuan, 1983, 1984, Ferreira dos Santos, 1987, Mello, 1991, 2000).

No Rio de Janeiro, a criatividade fértil de seu povo reflete-se, igualmente, através do repertório oral. Expressões e palavras como "vou descer, vou subir" ou "vou à Cidade", 
indicando direção ou procedência em relação à Área Central, popularmente denominada de Centro ou Cidade, fazem parte do vocabulário do carioca. O emprego de tais expressões, na Grande Tijuca, ou em qualquer outro ponto do município, assoma de forma desconcertante tendo em vista ser o mesmo, em toda a sua dimensão, oficialmente urbano. Trata-se de um meio peculiar e comum, possivelmente um legado dos tempos do Rio Colonial, quando o seu acanhado espaço urbano, propriamente dito, restringia-se à Área Central da atualidade. O carioca, do mesmo modo, aponta como sinonímia os vocábulos morro e favela. Na realidade, o acidente geográfico - morro - e o fenômeno da favelização se confundem na vida da cidade, a partir de 1893, com a ocupação, respectivamente, dos morros de Santo Antônio e da Providência, por soldados da Revolta da Armada (1893) e egressos da Campanha de Canudos (1897). A cidade, desde então, passou a denominar indiscriminadamente o morro e a favela, conseqüência de uma situação muito própria, qual seja a de um tipo de segregação espacial singular, com as pessoas de baixa renda ocupando, de maneira alternativa, as vertentes das montanhas, com seus barracões de madeira e zinco, outrora, e, ultimamente, casas de alvenaria, muitas delas inacabadas, em meio a vielas e becos, diferindo de outras cidades do Planeta, cujo tripé de amenidades, ou apenas um de seus itens - mar-verde-montanha - constitui elemento de atração para as pessoas de estratos de renda privilegiados. Desse modo, morro e favela confundem-se igualmente no linguajar dos moradores e freqüentadores da Grande Tijuca, cercada de elevações que abrigam algumas das mais famosas favelas da cidade, como a do Salgueiro, célebre por sua vitoriosa escola de samba, entre tantas outras favelas (ABREU, 1993, 1997; CORRÊA, 1989).

As situações acima encontram um traço comum na cidade. Todavia, o qualitativo tijucano apresenta uma condição notável, pois apenas os moradores da Tijuca são assim nomeados, havendo uma única aproximação com o gentílico suburbano, distinção conferida aos habitantes dos bairros pertencentes aos subúrbios da cidade.

No trato do uso dos nomes dos lugares alguns deles podem ser transitivos ou duradouros, sofrer uma espécie de torpor ou até mesmo fenecer, ao sabor das oscilações periódicas e de outras injunções. O exemplo do Andaraí é notório. Por questão de status, o bairro situado junto ao Grajaú e à Tijuca cada vez mais perde os seus domínios territoriais para estes bairros, seja por sugestão ou imposição dos incorporadores imobiliários, que veiculam partes de sua porção espacial como pertencentes aos citados bairros, com o objetivo de auferir lucros mais vultosos ou até mesmo por uma propagação "boca a boca", de modo que, nas próximas décadas, é possível que o Andaraí "suma do mapa", em detrimento do bairro do Grajaú, criado sob o modelo da cidade-jardim ou da Tijuca, aristocrático bairro, no passado, e, hodiernamente, reduto de classe média.

O rol de ilustrações do vocabulário carioca contempla cortes como aqueles referentes ao estádio esportivo do Maracanã - situado no bairro do mesmo nome - e popularmente chamado de "Maraca". Experiência, intimidade, urgência e habilidade conduzem a posturas como estas no dia-a-dia. Na trilha de eliminações, nomes oficiais são informalmente abandonados. Recorde-se, por exemplo, o costume do tijucano ao se referir à "Praça". O bairro, vale frisar, possui algumas praças, mas sabe-se que tal menção deve-se basicamente ao logradouro oficialmente denominado Praça Saens Peña, com sua rede de lojas, estabelecimentos comerciais, consultórios, cursos e, no espaço coletivo, bancas de jornais, mesinhas para jogos, disponibilidade de pistas para automóveis e uma ampla gama de linhas de ônibus, afora concorrida estação do metrô, "orelhões", e toda sorte de equipamento relativo a uma praça de bairro nobre. Ao lado disso, vale 
ressaltar, a referência ao bairro de Vila Isabel. Sua toponímia evoluiu, mais tarde, para uma associação a Noel Rosa, uma das maiores legendas das artes brasileiras em todos os tempos, morador e divulgador persistente dos (en)cantos, dramas e magia do bairro através de suas composições (motivo de destaque a seguir). Práticas como essa remetem ao princípio fenomenológico de imbricação - interiorização - pertencimento entre o indivíduo e o lugar. Como sublinha o geógrafo D. C. Pocock "na simbiótica relação entre homens e meio ambiente, lugares devem ser considerados como pessoas e pessoas como lugares" (Pocock, 1981:337). O nome de Noel Rosa, "o poeta da Vila”, mesmo após anos de sua morte, continua sendo motivo de superposição ao do bairro por ele tantas vezes divulgado em tons, versos e harmonia.

\section{A geografia da Grande Tijuca no ritmo das canções}

No Rio de Janeiro, estuário de manifestações artísticas e populares, pulsa uma geografia vívida, no compasso, nas notas e nas letras consignadas no cancioneiro popular. Neste diapasão, o presente artigo prossegue o seu curso focalizando um pequeno elenco de músicas dedicadas aos logradouros, fluxos ou bairros da Grande Tijuca. Para tanto, a avaliação do repertório musical com vistas à elaboração desta unidade obedecerá ao seguinte procedimento: cada uma das músicas será interpretada à luz dos versos das canções alinhadas em ordem cronológica e analisados na íntegra, quando necessário, ou apenas, parcialmente. Para cada melodia será considerado um breve apanhado biográfico dos compositores. Trata-se, na realidade, de uma manifestação cultural rica em depoimentos esculpidos por compositores oriundos dos mais diversos locais que revelam experiências com o seu grupo social e lugar, ou que comungam e se solidarizam com outros estratos sociais e lugares (MELLO, 1991).

A música popular, na verdade, carrega em seu bojo desde intelectuais de classes privilegiadas a cidadãos de origem humilde, incluindo até mesmo analfabetos. A força e os significados relatados pela literatura musicada emergem do íntimo, da alma dos compositores, a partir de suas vivências, concepções, entendimento e solidariedade, distante da dicotomia sujeitoobjeto. Neste sentido, a geógrafa Anne Buttimer (1985) lembra que muitas poesias e canções modernas são carregadas de emoção sobre o sentido do lugar.

\section{... São Paulo dá café, Minas dá leitel e a Vila Isabel dá samba}

$$
\text { ... (1934) }
$$

Na serenidade do samba-canção "Feitiço da Vila", levado ao disco em 1934 por Noel Rosa e João Petra de Barros, os compositores Noel Rosa e Vadico fazem a apoteose do bairro:

"quem nasce lá na Vila/ nem sequer vacila/ ao abraçar o samba/ que faz dançar os galhos do arvoredo/ e faz a lua nascer mais cedo/ o sol da Vila é triste/ samba não assiste/ porque a gente implora:/ sol! não venha agora/ que as morenas vão logo embora/ a Vila tem/ um feitiço sem farofa/ sem vela e sem vintém/ que nos faz bem/tendo nome de princesa/ transformou o samba/ num feitiço decente/ que prende a gente/ lá em Vila Isabel/ quem é bacharel/ não tem medo de bamba/ São Paulo dá café, Minas dá leitel e a Vila Isabel dá samba ... mas tenho que dizer, modéstia a parte/ meus senhores, eu sou da Vila! ...” 
O compositor Noel Rosa nasceu (1910) e morreu (1937) na "Cidade Maravilhosa". Branco, filho de gerente de uma camisaria e professora, "sofreu toda a vida as conseqüências de um parto difícil: o fórceps provocou fratura e afundamento do maxilar, além de ligeira paralisia na face direita, deixando-o desfigurado, apesar das operações realizadas aos seis e aos doze anos de idade" (Enciclopédia... 1977:670). Boêmio, padeceu de tuberculose durante parte de sua existência e em conseqüência das noitadas vividas intensamente. Uma das unanimidades nacionais, deixou aos vinte e seis anos de idade um fantástico acervo ainda hoje, mais de meio século após sua morte, amplamente cultuado. O compositor Vadico, filho de imigrantes italianos, nasceu no bairro do Brás, na capital paulista em 1910 e morreu no Rio de Janeiro em 1962. Todos os seus irmãos, como ele, eram músicos. Deixou a profissão de datilógrafo para tocar piano em público, pela primeira vez, em um hotel de Poços de Caldas, estado de Minas Gerais. Como compositor Noel Rosa escreveu diversas obras-primas e com Marino Pinto o clássico "Prece". Fez diversas orquestrações para filmes da "Pequena Notável", a cantora e atriz Carmem Miranda, nos Estados Unidos. Atuou também em vários países estrangeiros, sul americanos e na Jamaica. Em 1957, ingressou como diretor musical da Tv Rio, emissora da "Cidade Maravilhosa" (Enciclopédia ... 1977:775).

Na música da dupla Noel Rosa e Vadico o samba de Vila Isabel é sorvido como uma poção mágica “... que faz dançar os galhos do arvoredo/e faz a lua nascer mais cedo ....“. Notívago e, ao mesmo tempo, avesso aos universos solares, o samba do lugar, com suas morenas, vara a noite até a chegada do astro rei, o que faz os compositores implorarem: "... sol! não venha agora/ que as morenas vão logo embora ...”. Este patrimônio cultural (“... São Paulo dá café, Minas dá leite/e a Vila Isabel dá samba...") permite aos compositores igualar o bairro “... com nome de princesa ..." a duas das maiores Unidades da Federação: São Paulo e Minas Gerais, que se destacam, respectivamente, por suas produções cafeeira e leiteira, enquanto o bairro de Vila Isabel exibe o samba como uma manifestação repleta de "... feitiço decente/ que prende a gente ...".

... a Vila é uma cidade independentel que tira samba mas não quer tirar patente... (1936)

O samba "Palpite Infeliz" (1936) de Noel Rosa faz parte da antológica polêmica travada entre dois gênios da música popular brasileira: Noel Rosa e Wilson Batista. Na música, o "Poeta da Vila" começa provocando:

“quem é você que não sabe o que diz? Meu Deus do céu que palpite infeliz!/ salve Estácio, Salgueiro e Mangueira/ Oswaldo Cruz e Matriz/ que sempre souberam muito bem/ que a Vila não quer abafar ninguém/só quer mostrar que faz samba também/fazer poemas lá na Vila é um brinquedo/ ao som do samba dança até o arvoredo/ eu já chamei você pra ver/você não viu porque não quis/ quem é você que não sabe o que diz/ a Vila é uma cidade independentel que tira samba mas não quer tirar patentel pra que ligar a quem não sabel aonde tem o seu nariz?/ quem é você que não sabel o que diz”. 
No samba "Palpite Infeliz" em resposta aos desafios de Wilson Batista, o compositor Noel Rosa desfere a sua mágoa dizendo que a territorialidade do samba não pode se restringir a este ou aquele ponto da cidade. Noel que semeou, ao longo de sua curta e prodigiosa carreira, o amor pelo bairro de Vila Isabel, louva lugares tradicionais do samba carioca (“... salve Estácio, Salgueiro, Mangueira/ Oswaldo Cruz e Matriz..”), pela compreensão (“... que sempre souberam muito bem/ que a Vila não quer abafar ninguém/só que mostrar que faz samba também...”), ufana-se desmedidamente com respeito à cultura do lugar (“... fazer poemas lá na Vila é um brinquedo/ ao som do samba dança até o arvoredo...”) e desafia: “... eu já chamei você pra ver/ você não viu porque não quis/ quem é você que não sabe o que diz?..". Ao término da música, lançada nos idos de 1936, o compositor promove o bairro a uma outra categoria (“... a Vila é uma cidade independente...”), mas enfatiza: “... pra que ligar a quem não sabe! aonde tem o seu nariz?/ quem é você que não sabe/ o que diz?”.

No largo da Segunda-Feira/ onde eu morei um dia... Matoso, Praça da Bandeira/ meu caldo de cana/ as entradas, as bandeiras/ de fins de semana... (1972)

A balada memorialística "Largo da Segunda-Feira" de Roberto e Erasmo Carlos foi registrada em vinil por um dos seus autores, o cantor Erasmo Carlos, no ano de 1972:

"no largo da segunda-feira/ onde eu morei um dia/ entre gatos, periquitos/ plantei minha folia/ e era normal/ alçapões armados no meu quintal/surdo e fantasia no carnaval/ meus remédios, minhas pipas, meus colégios/ Matoso, Praça da Bandeira/ meu caldo de cana/ as entradas, as bandeiras/de fins de semana/ e era normal/ malhação de Judas da Aleluia/ as perguntas todas, banhos de cuia/ minhas dores, meus pecados, meus amores".

A dupla Roberto e Erasmo Carlos tem exercitado sua espantosa vocação para fazer sucesso ao longo de décadas. Roberto Carlos, natural de Cachoeiro de Itapemirim, estado do Espírito Santo, filho de relojoeiro e costureira, nasceu em 1943. Branco, católico, tomou-se o "Rei do yê, yê, yê", no Brasil, e por isso mesmo inicialmente atacado pela ala tradicional da música popular brasileira, por trabalhar longe de suas raízes. Seus programas de televisão, como "Jovem Guarda", com Wanderléia e Erasmo Carlos, ditaram moda, expressões, tendências e gírias, nos anos sessenta (Enciclopédia... 1977:716). Erasmo Carlos nasceu em 1941 no Rio de Janeiro. Estudou nos colégios Batista e Lafayette, no bairro da Tijuca. Com Roberto Carlos, parceiro constante, tem escrito mega-sucessos para discos, filmes e shows (Enciclopédia... 1977:251).

Nos versos da música em foco o astro Erasmo Carlos passa à posteridade o mundo vivido de seus tempos de criança e juventude no “... largo da Segunda-Feira/ onde eu morei um dia...”. Enrodilhado nas armadilhas das ternas lembranças do logradouro da Tijuca renasce uma miscelânea de “... periquitos...”, “... alçapões armados/'no meu quintal...”, “... fantasia no carnaval...”, “... pipas...” e “... colégios...”.

Na segunda parte da música, nos versos “... Matoso, Praça da Bandeira... as entradas, as bandeiras/ de fins de semana...” os autores estabelecem uma analogia entre o desbravamento dos 
primeiros exploradores do território brasileiro e o perambular dos jovens da "turma do Matoso" - rua com início na Praça da Bandeira, periferia da Área Central e parte da Grande Tijuca - e de onde saíram alguns músicos consagrados, como Roberto e Erasmo Carlos.

... mudou Vila Isabel ou mudei eu?/ Brasil .../ tá em falta o honesto sol do quarador ...(1972)

A música em tela tem o aval da dupla João Bosco e Aldir Blanc. O cantor e compositor João Bosco, mineiro de Ponte Nova, nasceu em 1946. Sua mãe tocava piano e violino, como a irmã, crooner em clube da referida cidade. João Bosco cresceu ouvindo todo tipo de música, embora cantasse rock no conjunto X-Garey, formado por amigos. Em 1962 foi para a cidade de Ouro Preto (Minas Gerais) estudar engenharia. Gozando férias, no Rio de Janeiro, em 1969, conheceu Aldir Blanc com quem passaria a escrever diversas e belas obras populares imortalizadas por alguns dos maiores nomes das artes brasileiras como Elis Regina, Marlene, Maria Alcina, Ângela Maria, Emílio Santiago, entre outros (Enciclopédia..., 1977:105). O carioca Aldir Blanc nasceu em 1946 e tem residido em bairros como Estácio e Tijuca. Começou a compor aos dezesseis anos de idade, foi baterista do conjunto Rio Bossa Trio, colou grau na Faculdade de Medicina e Cirurgia (Enciclopédia..., 1977:99) e é considerado um dos maiores letristas da música popular brasileira. Boêmio, intelectual, cronista e jornalista, Blanc conhece e transita pessoalmente, ou através de suas canções, por diversos mundos da "Cidade Maravilhosa".

Os acordes dos violões e a suavidade dos violinos antecedem à voz do cantor e compositor João Bosco na interpretação dos versos de "Tempos do Onça e da Fera" do parceiro Aldir Blanc: "saindo pro trabalho de manhã/o avô vestia o sol do quarador/tecido em goiabeiras, sabiás/ciganas, vira-latas e um amor/e o amor ia ao portão pra dar adeus/de pano na cabeça, espanador.. ./os netos ... o quintal... Vila Isabel.. ./-todo o Brasil era sol, quarador...”. Em outra parte da música os instrumentos mencionados cedem às guitarras elétricas, anunciando as metamorfoses sofridas pelo bairro: “... hoje acordei depois do meio dia/chovia, passei mal no elevador/ouvi na rua as garras do metrô/o avô morreu/mudou Vila Isabel ou mudei eu?/Brasil .../tá em falta o honesto sol do quarador...".

O poeta Aldir Blanc viveu a adolescência em Vila Isabel, bairro da zona norte da cidade nascido e pontilhado de vilas operárias, criadas junto a diversos estabelecimentos fabris e, atualmente, pleno de prédios de vários pisos habitados por pessoas de classe média. Saudoso de um tempo do "... sol do quarador ... sabiás/cigarras, vira-latas...”, o letrista recorda: “... — todo o Brasil era sol, quarador...". Com o passar dos anos as casas e os quintais de Vila Isabel desapareceram (“... chovia, passei mal no elevador...”). A expansão imobiliária (vertical) e o adensamento populacional provocaram a construção do solo subterrâneo. E, o compositor residindo, provavelmente próximo à Tijuca, bairro vizinho de Vila Isabel e por onde passam os trilhos do metrô, (“... ouvi na rua as garras do metrô...”) - na época do lançamento da música em fase de construção - com a perda de parte de sua identidade (“... o avô morreu/mudou Vila Isabel ou mudei eu?...”) constata desiludido: “... tá em falta o honesto sol do quarador...”.

... dobra a Carioca, olerêl desce a Frei Caneca, olará/ se manda pra Tijuca/ sobe o Borel ...(1978) 
Em 1978 Chico Buarque de Hollanda gravou o samba "Pivete", composto a quatro mãos com Francis Hime. Carioca, nascido em 1944, Chico Buarque de Hollanda, aos dois anos de idade, migrou com a família para São Paulo e com oito anos para a Itália, onde seu pai, o historiador Sérgio Buarque de Hollanda, fora lecionar. Chico Buarque não concluiu o curso da Faculdade de Arquitetura e Urbanismo da Universidade de São Paulo, iniciado em 1963, mas despontou como um dos maiores nomes da intelectualidade brasileira, com enorme prestígio popular (Enciclopédia..., 1977:346). Suas letras surpreenderam o país pela contundência de suas mensagens. Longos e apaixonados discursos musicados conquistaram o povo brasileiro com grande impacto e imensa repercussão. Seu parceiro Francis Hime nasceu em 1939, começou a estudar piano aos seis anos de idade e por quatro anos estudou na Suiça. Ao final da década de sessenta participou de vários festivais de música compondo com parceiros como Vinícius de Moraes. Entre 1969 e 1974 estudou regência, orquestração e composição nos Estados Unidos. Retornando ao Brasil, em 1974, passou a elaborar trilhas sonoras para filmes nacionais, além de compor vários sucessos (Enciclopédia..., 1977:344).

Na música "Pivete" os autores mapeando a dinâmica coreografia empreendida no dia-adia pelo menino constatam sua situação que a qualquer custo procura uma maneira de "ganhar a vida”: “... no sinal fechado/ele vende chiclete/capricha na flanela/e se chama Pelé...". O pivete Pelé, apelido alusivo ao atleta negro, procura vender qualquer objeto, aproveitando a brecha do “... sinal fechado... e recorre também à flanela para limpar o vidro do carro, para-assim tentar ganhar "algum trocado". A letra da música continua descrevendo ainda outras peripécias do pivete: “... pinta na janela/aponta um canivete/e até/dobra a Carioca, olerê/desce a Frei Caneca, olará/se manda pra Tijuca/sobe o Borel/meio se maloca/agita numa boca...”. O pivete, não conseguindo "um trocado", através da venda de algum produto ou do serviço de limpa-vidro, procura, por meio do uso coercitivo de um canivete, utilizado como arma, intimidar o transeunte. No caminho da fuga o pivete percorre a rua da Carioca, na Área Central do Rio de Janeiro, logradouro integrante do "Corredor Cultural", em seguida "... desce a Frei Caneca, olará...", rua com aglomeração de lojas especializadas em material de construção, na qual encontra-se, igualmente, localizado o Presídio do mesmo nome. Daí, então, “... se manda pra Tijuca/na contramão ... sobe o Borel ...“. No morro do Borel, situado no bairro da Tijuca, o pivete “... meio se maloca ...", em outras palavras, se esconde, e “... agita numa boca ...“, diz a música em alusão a um dos pontos de venda de drogas e de controle dos narcotraficantes (MELLO, 1991).

... num 433, Barão de Drumond/ pra Vila Isabel lá do fim do Leblon ... (1983)

A música “433”, composta por Bebeto Alves, foi gravada em 1983 pela dupla gaúcha Kleiton e Kledir:

"ai essa louca ilusão/que embola o meu coração/ num 433, Barão de Drumond/ pra Vila Isabel lá do fim do Leblon/ que rola na noite de alguma mesa/ um cheiro de pizza e cerveja/ segredo de um bar/ que rola na noite um beijo, um abraço/ nas ruas um olhar de cansaço/ sonho brasileiro de neón/ ai essa louca ilusão/ cintilando no meu coração/ uma estrela num ônibus da madrugada...”. 
O ônibus da linha 433 (Barão de Drumond-Leblon) liga os bairros de Vila Isabel e Leblon (bairro nobre, situado na Zona Sul do Rio de Janeiro). As companhias de ônibus - meio de transporte de massa mais intensamente utilizado na "Cidade Maravilhosa" - costumam retirar ou diminuir sobremaneira o número de veículos em circulação durante o período da madrugada. Entretanto, para quem habita na Área Central, Zona Sul e parte da Zona Norte da cidade próxima ao Centro, as alterações não são muito drásticas. Neste sentido, o balé do lugar, compreendido pelas migrações definitivas, ocasionais ou cotidianas e estabelecido por gestos, passos, itinerários e veículos (SEAMON, 1980), não se torna tão penoso. Assim, pode-se estender a noitada regada a cerveja, pizza e amor, em um bar do sofisticado bairro do Leblon, tornando-se depois "... nas ruas um olhar de cansaço...” a espera do 433, para então, finalmente, embarcar “... pra Vila Isabel lá do fim do Leblon...".

à minha direita raia um sol vermelho e branco/ à minha esquerda um verde e rosa vem dormir/ à minha frente ecoa um grito de gol/ atrás de mim dorme a Floresta do Andaraí ... (1984)

O samba "Flor dos Tempos", lançado em disco por Martinho da Vila, no ano de 1984, é de autoria de Ruy Quaresma e Nei Lopes:

“à minha direita raia um sol vermelho e branco/ à minha esquerda um verde e rosa vem dormir/ à minha frente ecoa um grito de gol/ atrás de mim dorme a Floresta do Andarail entre o Engenho Velho e o Novo ouço cantar/ um tangará nas ramas dos oitis do Boulevard/ aqui foi que os Drumond, os Rudge e os Maxwell/ vieram semear Vila Isabel,/ Vila, lá vou eu/ camisa aberta, ventre livrel chinelo nos pés/ da Barão de São Francisco, tomo um chopp no Petisco/faço uma fé no Cém Réis/Vila, Vila eu vou/ por entre as notas das calçadas musicais/ vou seguindo as partituras/ de tão sábias criaturas/ que fizeram sambas imortais/nossos laços são tecidos pela flor dos tempos idos/nos antigos carnavais".

O compositor Nei Lopes é escritor, colabora com o movimento negro e foi responsável pelo enredo da escola de samba Unidos de Vila Isabel, no ano de 1991. Seu parceiro, Rui Quaresma, além de compositor e instrumentista, é arranjador. Em "Flor dos Tempos", os autores Ruy Quaresma e Nei Lopes utilizam uma maneira absolutamente particular, e poética, para localizarem o bairro vivido. Como se sabe, as estrelas, o sol e a lua exercem papel marcante na orientação espacial da maioria dos povos de sociedades tradicionais. O homem urbano, ao contrário, parece não se incomodar muito em localizar-se no espaço a partir de astros e estrelas e nem sempre utiliza os pontos cardeais, mesmo sabendo que o sol nasce no leste ou se põe no oeste. O citadino, em sua vida prática, em muitas oportunidades, substitui tais referenciais por direita, esquerda, em cima ou em baixo. Na música "Flor dos Tempos", decodificando para uma linguagem da ciência espacial, entende-se que a leste situa-se o morro do Salgueiro, bairro da Tijuca, no qual está sediada a escola vermelha e branca dos Acadêmicos do Salgueiro, a oeste, o morro da Mangueira, cujas cores verde e rosa são defendidas pela escola de samba do mesmo nome, um dos símbolos da cultura nacional, ao norte o estádio do Maracanã e ao sul um dos 
grandes, e não raros, espaços verdes da "Cidade Maravilhosa", isto é, a Floresta do Andaraí. Os compositores focalizam e citam ainda outros pontos de referência do mundo vivido - cercado de morros e das culturas musical e esportiva - presenteado pelo canto do pássaro urbano em pleno Boulevard Vinte e Oito de Setembro, principal artéria do bairro, e única da cidade a ser lograda com tal distinção no idioma francês. Depois de situarem poética e geograficamente o lugar vivido e lembrarem a perfeita integração das naturezas natural-artificial, os compositores percorrem desde os primeiros momentos de sua ocupação, quando ainda era constituído por propriedades rurais até a descontração vivenciada nos anos oitenta, seja ao caminhar à vontade da rua Barão de São Francisco ao Petisco (restaurante cuja fama extrapola as fronteiras do bairro), seja fazendo “... uma fé no cém réis...", o velho hábito de "jogar no bicho", jogo de azar criado pelo Barão de Drumond. Por fim, os versos de "Flor dos Tempos" focalizam as “... calçadas musicais..." cujas pedras portuguesas reproduzem as partituras de melodistas que perpetuaram o bairro em suas composições, como Noel Rosa (1910-1937), por isso mesmo - vale repetir — consagrado como o "poeta da Vila".

... Vila Isabel/ bem ali entre Maracanã, Grajaú e Salgueiro/ é uma escola de samba famosa neste Brasil inteiro... (1984)

O samba "Nem a Lua" foi escrito por Martinho da Vila, Noca e Charlote. O compositor Martinho da Vila nasceu em 1938 em Duas Barras, município do estado do Rio de Janeiro. Aos treze anos tornou-se um "habitué" da escola de samba Aprendizes da Boca do Mato e aos quinze já compunha samba de terreiro. Em 1957 escreveu o primeiro de uma vitoriosa série de sambasenredo. Freqüentou até o terceiro ano o curso técnico de contabilidade. Serviu ao Exército Brasileiro, por treze anos (Enciclopédia... 1977:456) e participou de diversos festivais de música. Cantou a negritude, o papel da mulher na sociedade brasileira e a sua escola de samba Unidos de Vila Isabel - que lhe cunhou o apelido-sobrenome - e da qual foi, por muito tempo, diretor de harmonia e administrador da agremiação. Muito popular no país foi anunciado, ao integrar o júri do Festival da Canção Francesa, realizado em 1987, no Hotel Nacional, como "filho de Noel Rosa com a Mãe África". O compositor Noca (da Portela) é também negro e nasceu em 1932 no Rio de Janeiro. Filho de professor de violão, com a idade de quatorze anos, compôs um sambaenredo e, seguindo nesta trilha, foi admitido na ala dos compositores da escola de samba da Portela (Enciclopédia... 1977:537), agremiação esta que desfilou por diversos carnavais com músicas de sua autoria.

A parte selecionada da canção "Nem a Lua" praticamente repete a mensagem de "Flor dos Tempos" lançada no mesmo disco de Martinho da Vila em 1984. Desta feita os compositores, que se referem à escola de samba (Grêmio Recreativo Escola de Samba Unidos de Vila Isabel), e não ao bairro especificamente, são mais diretos e mencionam explicitamente o Maracanã e o Salgueiro, além do bairro de Grajaú, limítrofe à Vila Isabel, substituído no samba anterior pela Floresta do Andaraí. Entretanto, no samba "Nem a Lua", os autores - que utilizam outros elementos (escola de samba, bairros) - posicionam-se como "outsiders" quando cantam “... Vila Isabel/bem ali entre Maracanã, Grajaú e Salgueiro...” (MELLO, 1991).

Do lirismo, da crítica, da contundência e do balanço oferecidos pelo cancioneiro popular consideremos a seguir alguns dos lugares centrais da Grande Tijuca. 


\section{Os lugares centrais da Grande Tijuca}

A Grande Tijuca é uma porção da cidade do Rio de Janeiro plena de centralidades construídas, eleitas ou adotadas pelos indivíduos e grupos sociais. Mas, o que vem a ser centralidade, um lugar central? A centralidade assume as mais diversas facetas em diferentes escalas. Uma cabine telefônica, um cinema, um templo ou o endereço domiciliar são lugares centrais, porque atraem usuários e irradiam idéias e significados. Em outro extremo, a cidade, a região, a pátria ou até mesmo o Planeta Terra - nestes tempos de consciência ecológica podem adquirir simbolicamente o status de lugares centrais.

Os geógrafos conceituam um lugar central por ser um ponto de concentração e irradiação de fluxos comerciais, financeiros, sociais, administrativos etc. A centralidade, sob este prisma, diz respeito à relevância de um ponto enquanto lugar central, expressa pela magnitude dos bens e serviços oferecidos e por sua respectiva área de influência. Afora esta tendência, vale lembrar que, a corrente humanística na Geografia aprecia a dimensão etnocêntrica como algo concernente aos lugares centrais (TUAN, 1980). No entanto, a centralidade não se encerra neste círculo. Uma pluralidade de perspectivas sobre o assunto merece ser analisada a despeito da existência de uma complexa gama de centralidades que se entrelaçam ou ocorrem isoladamente (MELLO, 1995, 1997).

$\mathrm{Na}$ Grande Tijuca, o mosaico de centralidades encerra lugares centrais como os subcentros Tijuca e Vila Isabel, os shopping centers Tijuca Off e Iguatemi, o Maracanãzinho, a Uerj (Universidade do Estado do Rio de Janeiro), templos religiosos, entre outras.

À guisa de explicação, pontuemos, inicialmente, as diferenciações entre bairro e subcentro. Bairros de segmentos de diversos tipos de renda voltados especialmente para a questão da moradia possuem diversos prédios e casas, bem como um tímido comércio, no qual são supridos os bens e serviços mais freqüentes e que podem ser encontrados em estabelecimentos como padarias, açougues, farmácias, bares ou bancas de jornais ou nos consultórios médicos de clínica geral. Seus comerciantes, como sublinha Corrêa (1989:51), "são moradores do bairro e conhecidos dos fregueses". Parte do bairro salta desse estágio de comércio e serviços incipientes para a condição de subcentro quando dispõe, entre outros fatores, de amenidades e uma ampla acessibilidade, por ser um ponto de concentração ou um eixo percorrido por pessoas do próprio bairro e das circunvizinhanças (que formarão a clientela e a área de influência do subcentro emergente). Esta espécie de vitrine coletiva atrai usuários e consumidores que procuram centros que apresentam uma certa gama de bens e serviços. O processo de descentralização e conseqüente gênese ou cristalização dos subcentros está condicionado, entre outros fatores, aos crescimentos espacial e demográfico da cidade aliado às facilidades de transporte, infra-estrutura implantada, qualidades atrativas do sítio e amenidades (CORREA, 1989:46).

No Rio de Janeiro o fenômeno da descentralização não é muito recente, pois enquanto a cidade permaneceu acanhada, atividades como aquelas referentes ao ramo manufatureiro encontravam-se na área na qual hoje situa-se o centro da "Cidade Maravilhosa". Todavia, a dinâmica da descentralização dos estabelecimentos industriais "começou a se delinear ainda ao final do século passado" (CARDOSO, 1986:21), dirigindo-se para São Cristóvão e Vila Isabel, Tijuca ou Andaraí, em razão da infra-estrutura urbanística e a existência de rios. Esses bairros, nos dias de hoje, entretanto, são eminentemente residenciais e dotados de estabelecimentos 
comerciais e de serviços, notadamente Tijuca e Vila Isabel. Trata-se da questão relativa à descentralização, dinâmica esta que não esvazia o centro da cidade, apenas modifica o seu papel, minimizando o peso da variada carga da oferta e da demanda de funções. Assim sendo, o surgimento de centralidades como os subcentros facilita a vida das pessoas ao oferecer o aparato necessário para compra, troca, venda e obtenção de bens e serviços. Nestes termos, a cadeia de lojas e estabelecimentos disposta junto ou próxima ao lugar vivido de moradia, constitui-se, da mesma forma, em lugar vivido dos encontros, do lazer, das compras e do trabalho, para os moradores do bairro que contempla o subcentro em seus domínios e para a sua respectiva área de atuação composta pelos bairros das redondezas (CORRÊA, 1989, MELLO, 1995, 1997).

O subcentro Tijuca apresenta-se como um exemplo notório de centralidade com sua enorme rede de lojas de departamentos, consultórios, estabelecimentos bancários, unidades e galerias comerciais, clubes esportivos etc. No entanto, se no passado, de acordo com Duarte (1974), os cinemas de rua, a partir da efervescência conferida por essas casas de espetáculos, provocaram o surgimento do subcentro, neste final de milênio, seguindo uma tendência persistente no Rio de Janeiro, apenas o Tijuca Off Shopping possui, em seu interior, esse tipo de estabelecimento de cultura e entretenimento.

O subcentro Vila Isabel, por seu turno, beneficiado ou sofrendo a concorrência do bairro e subcentro Tijuca, a cada instante surpreende ao posicionar-se como uma centralidade, em muito ajudada pela fama proporcionada por sua vida boêmia. A principal artéria do bairro, o bulevar Vinte e Oito de Setembro é, por excelência, o corredor dinâmico de unidades comerciais e de serviços, o qual derrama, para as ruas transversaís, um pouco do seu movimento de centralidade emergente.

Dos subcentros de rua, como Tijuca e Vila Isabel, passemos a seguir para os shopping centers, outra espécie de centralidade, todavia, confinada em meio a vidros, paredes, luxo e riqueza. Nas últimas décadas, como resposta à violência que assusta a cidade, o carioca passou a se enclausurar com o emprego de grades, muros e portões. Nestas circunstâncias, os shopping centers se adequam às exigências dos indivíduos e grupos de média ou alta rendas, que buscam segurança nesses refúgios ou feudos planejados de compras e lazer. Na realidade, no âmbito do espírito dessa agorafobia, construções como o Tijuca Off Shopping e o Shopping Center Iguatemi (bairro de Vila Isabel), despontam como centralidades apropriadas a esses tempos de exacerbado enclausuramento.

A arquitetura "envoltória que abriga (e) polariza" (BIENNESTEIN, 1993:52) o shopping center limita "uma mini-cidade dentro da metrópole" (BIENNESTEIN, 1993:24), "um espaço de lazer e sociabilidade, em especial para jovens, como canal alternativo para o comércio varejista, em particular dos bens e serviços ligados ao corpo e à casa, ao gosto e à moda" (PINTAUDI, FRUGOLI, 1992:43).

Shopping center significa, como o próprio nome indica, um centro de compras (e de serviços). Criado para atender a estratos sócio-econômicos específicos, caracteriza-se por ser um local que atrai pessoas que se identificam de alguma maneira e, portanto, são espaços que segregam, contribuindo para fragilizar as relações sociais. Fator de mudança na expansão urbana, no shopping center pulsa o "mundo rebrilhante e ofuscante das mercadorias", "possibilidade do consumo, do convite ao sonho, da falsificação da realidade" (PINTAUDI, FRUGOLI, 1992:IV). Fora dele há toda "sorte de mazelas que compõem o melancólico quadro que se apresenta no fim desse século, principalmente, para os países do denominado Terceiro Mundo" (BIENNESTEIN, 
1993:23).

O shopping center - construído em consonância com os ditames estadunidenses - seria o coroamento do patamar mais radical e sofisticado da natureza (re)elaborada pelo homem? A chamada "catedral do consumo", "subcentro fechado e de luxo", ou como quer que seja rotulado, não deve ser confundido, a ressalva é relevante, com galerias comerciais (neste caso, o Shopping 45, situado na Praça Saens Peiia, Tijuca, não pode ser classificado como shopping center). Enclave glamuroso e das maravilhas, onde os passantes são belos ou assim se fazem, por suas roupas e ainda pela conduta, esse rincão da pós-modernidade, como nos lindos sonhos de fadas, reproduz paraísos encantados, oferecendo para os seus "eleitos" comodidade, música, pequenos lagos e canteiros, iluminação feérica, comércio e serviços refinados, além de proteção contra a violência, a poluição, as intempéries e a pobreza ou miséria do "mundo exterior" (MELLO, 1993). Neste contexto, o Shopping Center Iguatemi e o Tíjuca Off Shopping, rompendo com a forma tradicional dos centros de compras, juntam-se à plenitude exibida por outras centralídades do Rio de Janeiro tais como o Rio Sul, o Barra Shopping, o Norte Shopping, o Madureira Shopping Rio e oWest Shopping.

O leque de lugares centrais se ocupa a seguir da concorrida centralidade despertada pelo Maracanãzinho, cujo nome oficial - Ginásio Gilberto Cardoso - homenageia o ex presidente do Clube de Regatas do Flamengo que teve morte fulminante ao final de um jogo de basquete vencido por sua equipe na decisão do campeonato carioca em 1955. O Maracanãzinho, fruto do trabalho humano, é um fixo social (SANTOS, 1988), elevado à categoria de referencial geográfico, de simbologia extremamente significativa, capaz de substituir a própria denominação da cidade. Isto porque, no Brasil, quando se menciona o cognome Maracanãzinho, surge, imediatamente, a lembrança da "Cidade Maravilhosa". Este centro de atração e arena de paixões inflamadas, não é dedicado exclusivamente às competições de basquete, voley ou ginástica olímpica, pois além de ter sido palco dos lendários concursos de misses de outrora e sediar o campeonato mundial de basquete de 1963, no qual o Brasil sagrou-se bi-campeão mundial, permanece sendo utilizado para a realização de shows, espetáculos de ballet, festivais de música, congressos religiosos, missas, formaturas, apresentações circenses etc, que sobrepujam sua própria destinação como centro esportivo.

Situada nas proximidades do Maracanãzinho, a Uerj - Universidade do Estado do Rio de Janeiro, próximo lugar central a ser destacado, reúne uma série de centralidades a partir de sua função educacional. A UEG, atual Uerj, ampliou o quadro de seus diversos cursos de licenciatura, bacharelado, extensão, pós-graduação, mestrado e doutorado que provocam ou irradiam várias outras centralidades em um universo de aulas, encontros, seminários, congressos concorrendo para a emergência de cantinas, quiosques, teatros, ginásio esportivo, agência bancária, concha acústica, capela ecumênica, livraria, editora, bibliotecas, galeria de arte, banca de jornal/revistas e estacionamento no campus inaugurado em 1975 (VINCENZI, 1999), na fronteira dos bairros do Maracanã e Vila Isabel.

Finalmente, este artigo ressalta as centralidades religiosas da Grande Tijuca, que logicamente não destoam de outras igrejas, templos e terreiros da cidade. Na realidade, os centros destinados aos cultos religiosos, diferem tanto nos dogmas, na profissão de fé e orações quanto no formato estético dos seus prédios.

A pompa arquitetônica das igrejas católicas faz parte da história e do espaço geográfico da cidade. São construções seculares, em estilos diversos, dominando ou integradas à paisagem 
como as igrejas de São Francisco Xavier, de São Sebastião (Capuchinhos), de Santo Afonso, dos Sagrados Corações, na Tijuca, ou de Nossa Senhora de Lourdes, em Vila Isabel, para citar apenas algumas delas, que atraem notadamente fiéis para os cultos, atos de introspecção, procissões, reuniões de grupos de apostolado e catequese. Do mesmo modo, os templos presbiterianos, batistas, metodistas e neopentecostalistas estão sediados em vários pontos da Grande Tijuca. Salta aos olhos, contudo, o crescimento de adeptos dos ramos neopentecostalistas, que no afã de transmitir a palavra do Senhor a todos os homens, não apenas constroem igrejas como convertem espaços esportivos, cinemas ou a rua em centros de orações e evangelização.

Quanto aos centros espíritas, terreiros de macumba e barracões de candomblé a característica dominante é o aproveitamento de casas residenciais — por vezes utilizando-se apenas algumas de suas dependências - para sessões de mediunidade, batuques e cerimônias fetichistas (MELLO, 1995, 1997).

A GEOGRAFIA DA GRANDE TIJUCA NA ORALIDADE, NO RITMO DAS CANÇÕES E NOS LUGARES CENTRAIS

Resumo: O artigo, afinado com os princípios da geografia humanística, que procura entender a alma dos lugares a partir das experiências vividas pelos indivíduos e grupos sociais, explora tons e versos dedicados aos bairros da chamada Grande Tijuca, bem como seus diversos lugares centrais, utilizando ainda a oralidade como instrumento de pesquisa para a compreensão desta porção espacial da cidade do Rio de Janeiro.

Palavras-chave: lugar, geografia humanística, oralidade, música, centralidade.

\section{GEOGRAPHY OF GREAT TIJUCA IN ORALITY, RHYTHM OF MUSIC AND CENTRAL PLACES}

Summary: This article, on the principles of humanistic geography, aims to understand the "soul" of places through lived experiences of individuals and social groups, exploring tones and verses related to districts of so-called Great Tijuca, as well its many central places, by the use of orality as an instrument of research for the comprehension of this spatial part of Rio de Janeiro city.

Keywords: place, humanistic geography, orality, music, centrality.

\section{Bibliografia}

ABREU, M. A. 1997. Evolução urbana do Rio de Janeiro. Rio de Janeiro: IPLAN. ABREU, M. A. 1993. A favela está fazendo cem anos. $3^{\circ}$ Simpósio Nacional de Geografia Urbana. Rio de Janeiro.

BIENNESTEIN, G. 1993. Acumulação de capital e espaço urbano: O exemplo do shopping center. Dissertação de Mestrado, Departamento de Geografia: UFRJ.

BUTTIMER, A. 1985. Hogar, campo de movimento y sentido del lugar. In: GARCIA RAMON, M. D.: Teoria y método en la geografía humana anglosajona. Barcelona, Ariel. 227-241.

CARDOSO, E. D. 1986. O capital imobiliário e a expansão da malha urbana no Rio de Janeiro: Copacabana e Grajaú. Dissertação de Mestrado. Orientador: Roberto Lobato Corrêa.UFRJ.

CORRÊA, R. L. 1989. O espaço urbano. São Paulo: Ática. 94p.

DUARTE, H. S. B. 1974. A cidade do Rio de Janeiro - descentralização das atividades terciárias. Os centros funcionais. Revista Brasileira de Geografia, Rio de Janeiro, 36 (1): 
53-98. Enciclopédia da música brasileira: erudita, folclórica e popular 1977. São Paulo: Art (2 volumes)

FERREIRA DOS SANTOS, C. A. 1987. Enredos e cidades - uma história antiga e uns ensinamentos recentes. II Encontro nacional sobre ensino arquitetônico. P. Alegre: FAU/UFRS.

MELLO, J. B. E de. 1991. O Rio de Janeiro dos compositores da música popular brasileira 1928/1991 - uma introdução à geografia humanística. Orientador: Roberto Lobato Corrêa. Dissertação de Mestrado, UFRJ. 1993. A humanização da natureza: uma odisséia para a (re)conquista do paraíso. In: SILVA, S. e VIANA, O. Geografia e questão ambiental. Rio de Janeiro: IBGE, 31-40 p. 1995. Explosões e Estilhaços de Centralidades no Rio de Janeiro. Espaço e Cultura, Rio de Janeiro: NEPEC/UERJ, (1): 23 - 44. 1997. Explosões e estilhaços de centralidades no Rio de Janeiro. GeoUERJ. Rio de Janeiro, UERJ, Departamento de Geografia (2): 51- 64. 2000. Dos espaços da escuridão aos lugares de extrema luminosidade - o universo da estrela Marlene como palco e documento para a construção de conceitos geográficos. Orientador: Roberto Lobato Corrêa. Tese de Doutorado, UFRJ.

PINTAUDI, M. S. e FRUGOLI, H. (org.). 1992. Shopping Centers. Espaço, Cultura e Modernidade nas Cidades Brasileiras. São Paulo: Editora UNESP.

POCOCK, D. C. D. 1981. Place and the Novelist. Transactions of the Institute of British Geographers. New Series 6, 337-347.

SANTOS, M. 1998. Metamorfoses do espaço habitado. São Paulo: Hucitec.

SEAMON, D. 1980. Body-subject, time-space routines and place-ballets. In: BUTTIMER, A. and SEAMON, D. The human experience of space and place. New York: St. Martin's Press.

TINHORÃO, J. R. 1969. Pequena História da Música Popular. Petrópolis: Ed. Vozes.

TUAN, Y E 1980. Topofilia. São Paulo: DIFEL. 1983. Espaço e lugar São Paulo: Difel. 1984. Dominance and Affection: The Making of Pets. New Haven: Yale Univ. Press.

VINCENZI, L. J. B. 1999. UERJ: da rua Haddock Lobo ao Maracanã. IN: WEYRAUCH, C. S., MOTA, M. S. Tijuca - memória, história e cultura. Rio de Janeiro: UERJ, DeCult, $147-158 \mathrm{p}$. 